\title{
INDEX OF SURGICAL PROGRESS.
}

\section{CHEST AND ABDOMEN.}

I. A Case of Pneumonectomy. By D. Lowsox (Hull) The patient, a female aged thirty-four, presented herself with the following history :

She had been married thirteen years, but had no children. She had suffered for fifteen years from dyspepsia, but for twelve months had much pain over the top of the right lung, striking through to the back, and had lost. much flesh. She frequently perspired at night, and often found herself bathed in perspiration in the morning. She'had a short cough, but no hamoptysis. The pulse was quickened, averaging $I I 2$, and the temperature in the evening was frequently $z^{\circ}$ to $3^{\circ}$ above normal.

There was distinct retraction below the right clavicle when compared with the left side. Dulness was also marked as far as the second space, and the voice sounds were much more loudly conducted on the affected side. The exaggeration of the vocal fremitus was very distinct when the two sides were compared. The family history was good. She herself had been a weakly girl, and had suffered from a suppurating gland on the right side of the neck. She was under observation for six months, and during that time the symptoms became gradually worse. The loss of flesh was inanifest, and the cough and perspirations continued to trouble her, though there was little expectoration and never any hæmoptysis.

Lowson came to the conclusion that, as far as one could judge by physical signs, the disease was probably confined to the right apex. The patient, also, though evidently losing ground, was not very ill. She, therefore, was a case suitable for operation, if a case 
could be. In addition, she was in poor circumstances, and could not afford the luxury of a change of climate.

An incision was made from mid-sternum along the course of the second rib, through the pectoral muscle nearly to the edge of the anterior axillary fold. From the inner end of this an incision was carried for a comple of inches downward along the middle of the sternum. The skin and muscle were then reflected from the surface of the second and third ribs, and a number of vessels spouted and were secured-mainly branches of the acromio-thoracic and intercostals. The external intercostal muscles were next separated above and below from the two ribs, and with a periosteal elevator the pleura was detached and stripped off from the inner side. With a fine saw the ribs were divided, through the cartilage internally and through the bone externally near the outer angle of the incision. Pinching up the pleura a trocar was pushed in, the cannula of which was connected by tubing with a Junker's bottle and bellows, and air, which was passed through a hot strong solution of carbolic acid, was slowly pumped into the pleural cavity. The lung could be partially seen sinking slowly from the chest wall, but no dyspnoa or cyanosis followed. The external layer of the plenra was next laid open the length of the external incision, and the lung found completely collapsed and moving up and down rhythmically with the diaphragm.

There were extensive adhesions along the face of the upper lobe, which took a considerable time to tear throngh, but gradually, and with patience, a complete separation was effected. There remained high up two finger-like ligamentous processes, attaching the apex to the summit of the extension into the neck. These were easily broken and the apex drawn out. The diseased part was seen occupying the anterior part of the apex. A large needle in a handle, rounded and without edge, and with an eye big enough to take in a large twisted silk thread, which had been boiled and had long lain soaking in an ethereal solution of jodoform, was employed. With this needle the lung was transfixed some distance below the disease, tied firmly in two pieces, after the Staffordshire method, and the upper diseased 
portion cut off. The portion renoved was the size of half a fist, and contained a dense tuberculous mass with discrete granulations around it. Into the stump iodoform powder was ruobed, the cavity was sponged out and the mutilated lung dropped back. In the course of the operation the whole organ was palpated for other collectious, but nothing was found except soft spongy lung tissue. The author was struck by the ease with which a living lung can be palpated. The fingers seem to almost meet, even when the thickest portions are grasped, nor do they seem so voluminous as in necropsies. The external incision was closed withont draining. At no time did the respiration get troublesome, so that neither the oxygen nor electric apparatus was wanted. The evening temperature was $99^{\circ}$ and pulse $8_{4}$; respirations, 36 .

For the next three days matters went on in a similar way, and all seemed going on well. On the night of the fourth day, however, there was a sudden development of a limited patch of dry pleurisy on the left side (opposite) which gave her much pain and greatly crippled the respiration, which increased in frequency to 46 per minute. The pulse also went up to ros, but the temperature stood at $99.6^{\circ}$. The trouble gradually disappeared, and the respirations fell to 28 .

The next difficulty rose at the end of the second week, when the temperature began to rise, every night going up until it reached 101. $6^{\circ}$. It seemed like a fresh eruption of tubercle. The breathing became a little quicker ( 32$)$, but the pulse was quiet ( 88 to 96 ). There was some dulness posteriorly, and, as some black blood had appeared at the outer angle of the wound on the fourth day, the author came to the conclusion that there was blood in the pleura, and it was this that was causing the rise of temperature, just as in cases of hæmatocele of the broad ligament.

The temperature kept up until a month after the operation, when there was a sudden discharge of a large quantity of brown looking matter of the color of chocolate, evidently altered blood. The tenperature now dropped to normal, and respirations to 24 . The 
hæmothorax now became an empyema. The brown color gradually changed to yellow, but at the same time the quantity diminished very much, and remained perfectly sweet. At the present time the amo:nnt drawn is not quite an ounce. The patient is thin, but is taking her food well and has been up on several occasions. The temperature has been normal for a long time, and the respirations averaged 22 . On the left side only healthy signs are discoverable; on. the right side clearness posteriorly, except in the upper scapular region, and in front clear below and hyper-resonant on gentle percussion over the part where the ribs were excised. Air seems to enter the lung well in the lower parts, and ordinary respiratory sounds are also heard in the suprascapular fossa. In the subclavicular fossa are the sounds produced by the air entering the small opening in the chest wall.

The author regrets that he did not introduce a drainage tube at the beginning. This, he thinks, would have hastened very much the ultimate healing.

The patient has steadily gained flesh and strength, and at the time of writing was up and about and preparing to return to her home.-British Wedical Journal, June 3, I $S_{93}$.

Jajies P. Warbasse (Brooklyn).

II. Hernia of the Vermiform Appendix; a Report of Forty-one Cases. By Dr. Brieger (Breslau). The author presents a series of forty-one cases: In twenty cases it was of the inguinal variety; in fifteen cases the femoral; in six cases the variety was not stated. In twenty-three cases the appendix was incarcerated; in seven it was reducible, and in eleven the condition was not stated. In only eight cases was the appendix normal. Operation was performed in twenty-six cases; sixteen cases were entirely cured; two were cured, bnt had a fistnlons opening; five died; in three cases the result was not stated.

As the study of the cases had advanced, the prognosis, which was formerly unfavorable, has of late become much more favorable.

From a careful study of these cases, he draws the following conclusions : 